\title{
Presentation and Differential Diagnosis of Hyponatremia in a Schizophrenic Adult Male
}

\author{
Michael J. Sedlacek, MD \\ University of Nebraska Medical Center
}

Follow this and additional works at: https://jdc.jefferson.edu/jeffjpsychiatry

Part of the Psychiatry Commons

Let us know how access to this document benefits you

\author{
Recommended Citation \\ Sedlacek, MD, Michael J. (1988) "Presentation and Differential Diagnosis of Hyponatremia in a \\ Schizophrenic Adult Male," Jefferson Journal of Psychiatry. Vol. 6 : Iss. 1 , Article 5. \\ DOI: https://doi.org/10.29046/JJP.006.1.003 \\ Available at: https://jdc.jefferson.edu/jeffjpsychiatry/vol6/iss1/5
}

This Article is brought to you for free and open access by the Jefferson Digital Commons. The Jefferson Digital Commons is a service of Thomas Jefferson University's Center for Teaching and Learning (CTL). The Commons is a showcase for Jefferson books and journals, peer-reviewed scholarly publications, unique historical collections from the University archives, and teaching tools. The Jefferson Digital Commons allows researchers and interested readers anywhere in the world to learn about and keep up to date with Jefferson scholarship. This article has been accepted for inclusion in Jefferson Journal of Psychiatry by an authorized administrator of the Jefferson Digital Commons. For more information, please contact: JeffersonDigitalCommons@jefferson.edu. 


\title{
Presentation and Differential Diagnosis of Hyponatremia in a Schizophrenic Adult Male
}

\author{
Michael J. Sedlacek, M.D.
}

The diagnosis of hyponatremia can prove to be a challenging task since initial symptomatology may mimic psychiatric illness. Accurate diagnosis and subsequent treatment is essential as this disorder can progress to seizures, coma and death if not recognized. Neither the true incidence nor the etiology of hyponatremia in the schizophrenic population has been established, but a definite association has been shown to exist. A recent retrospective study involving over 20,000 hospital admissions found a $5.8 \%$ incidence of hyponatremia in the schizophrenic population as compared with a $0.36 \%$ incidence for all admissions (1). The following case illustrates the features of hyponatremia and highlights the difficulties in identifying the illness in patients with schizophrenia. A discussion of the etiology, differential diagnosis and treatment follows, with the aim of increasing awareness of this potentially serious disorder.

\section{CASE REPORT}

Mr. M was a 52 year old Hispanic male with a long history of chronic undifferentiated schizophrenia, who was brought by his family to the emergency room with a three day history of agitation, confusion, headache, "not feeling well," difficulty walking, and recurrent falls. The patient had been well maintained previously on fluphenazine $5 \mathrm{mg}$ qid and benztropine $1 \mathrm{mg}$ tid. Several weeks previously, inapamide $2.5 \mathrm{mg}$ bid had been added for hypertension, which produced satisfactory blood pressure control. The family felt Mr. M had been compliant with medications. The patient denied illicit drug use and gave a 60 pack-year smoking history. Extensive contusions on his forehead and the bridge of his nose prompted skull x-rays, which were normal. It was initially felt that the patient's increasing agitation, confusion and uncooperativeness demonstrated an exacerbation of his psychiatric condition, and he was thus referred for psychiatric admission.

Upon psychiatric examination, slurred speech, ataxia and severe restlessness were immediately noted. The patient attempted to respond to verbal commands but had difficulty with speech and other complex motor behaviors. His recent peculiar behavior had been attributed, by his family, to an increase in auditory hallucinations. They then provided a history of decreasing appetite and very large consumption of water by the

Dr. Sedlacek is a third year resident in psychiatry at the University of Nebraska Medical Center, Omaha, Nebraska. 
patient over the past week. Other than occasional labile laughter, the mental status examination did not reveal any gross psychotic or affective abnormalities. Mr. M was oriented to person, place and time, but displayed poor concentration and cognition.

Physical examination revealed a $\mathrm{BP}$ of 210/130 and a pulse of 100 . Multiple ecchymotic areas about the face, hips, knees, and elbows were attributed to numerous falls. His pupils were $5 \mathrm{~mm}$ and sluggishly reactive. He was unable to cooperate in formal extraocular muscle testing, but was able to look in all directions. No doll's eye movements were noted. Battle's sign was negative. The patient's lungs were clear to ausculation and his cardiac examination revealed tachycardia without a murmur. Abdominal examination was normal. The patient showed a good range of motion and had symmetric, though diminished, strength in all extremities. He was unable to ambulate without assistance and had a very wide-based gait. Cranial nerves tested within normal limits. Patellar reflexes were +2 and symmetric; biceps and triceps were +1 . No clonus was noted and toes were down-going on Babinski.

Initial laboratory values were as follows: sodium $109 \mathrm{meq} /$ liter, potassium 3.1 meq/liter, chloride $69 \mathrm{meq} /$ liter, $\mathrm{CO}_{2} 24 \mathrm{meq} /$ liter, serum osmolality $233 \mathrm{mosmol} / \mathrm{liter}$, BUN $16 \mathrm{mg} / \mathrm{dl}$, and creatinine $1.3 \mathrm{mg} / \mathrm{s.c}$, glucose $148 \mathrm{mg} / \mathrm{dl}$, WBC 23,000 with 75\% segmented neutrophils and $6 \%$ bands, $\mathrm{Hgb} 16.8 \mathrm{gm} \%$, sedimentation rate 0 . Urine alcohol and drug screens were negative. Urinalysis showed a specific gravity of $1.010,1+$ protein and 3-5 RBC/HPF, urine osmolality $298 \mathrm{mosmol} /$ liter. Thyroid profile was normal. A CT scan of the head was obtained to rule out subdural hematoma or tumor, and was reported as normal.

It was now felt that the patient's ataxia and altered state of consciousness were secondary to hyponatremia. The patient was placed on fluid restriction of $500 \mathrm{cc} /$ day. The inapamide was initially replaced with hydralazine with subsequent blood pressure reading of $160 / 80$. The patient was next, and finally, placed on metaprolol $100 \mathrm{mg}$ bid with good blood pressure control. The following morning, although his serum sodium had increased to $118 \mathrm{meq} /$ liter, Mr. M became extremely agitated, requiring both soft physical restraints and sedation with chlorpromazine. Lumbar puncture performed at that time showed no evidence of CNS infection. With 4 days of fluid restriction, the patient's serum sodium returned to normal, and with this his agitation, delirium and ataxia resolved. Fluphenazine $5 \mathrm{mg}$ qid and benztropine $1 \mathrm{mg}$ tid were reinstituted on the second hospital day to treat his schizophrenic illness, without a return of hyponatremia. By the fifth day after admission, Mr. M was able to walk without assistance, and was felt stable enough to be discharged at that time. His blood pressure remained well controlled on metaprolol, with electrolytes remaining normal through five months of follow-up. The patient then transferred from the system and was lost to subsequent follow up.

\section{DISCUSSION}

The case of Mr. M illustrates many of the common early symptoms associated with hyponatremia, notably lethargy, weakness, somnolence, confusion, headache and anorexia. If hyponatremia progresses unnoticed, these symptoms are followed by seizures, coma and death. The ultimate key to diagnosis is maintaining clinical suspicion, followed by confirmatory laboratory evaluation, but the following additional clues may be helpful: 1) true weakness, as opposed to fatigue; 2) a history of a large fluid intake; 3) recent administration 
of drugs, e.g. diuretics or psychotropics; 4) the presence of other illnesses, e.g. diabetes; or 5) unexplained weight loss, possibly indicative of carcinoma (2).

Had Mr. M presented to any emergency room with the above symptoms, but without a previous diagnosis of schizophrenia, a complete metabolic and neurologic evaluation, no doubt, would have been undertaken without delay. However, based on his family's report of increased agitation and presumed worsened auditory hallucinations, his condition was assumed initially to be an acute exacerbation of chronic schizophrenia and hence an indication for psychiatric treatment. Mr. M's case illustrates the need for a high index of suspicion in patients who present with these seemingly rather nonspecific symptoms.

Once suspected however, the following factors also complicated the diagnostic picture in $\mathrm{Mr}$. M, since they have been known to be associated with hyponatremia: 1) the use of antipsychotic medication; 2) compulsive water consumption; 3) diuretic therapy; and 4) cigarette smoking.

The incidence of psychotropic drug-induced hyponatremia may be higher than some published reports have indicated. A general estimate of two or three cases per year at a tertiary care hospital is reasonable (2). Fluphenazine and several other psychotropic medications have been reported to be associated with hyponatremia due to the Syndrome of Inappropriate Secretion of Antidiuretic Hormone (SIADH) (3). Other psychiatric medications that have been associated with SIADH include amitriptyline, thiothixene, thioridazine, haloperidol, desipramine, carbamazepine, tranylcypromine, and the barbituates. The criteria for SIADH (4) includes: (1) hyponatremia with hypo-osmolar serum; (2) relatively large amounts of urine sodium with less than maximally dilute urine relative to plasma osmolality; (3) no clinical evidence of volume depletion or overload; (4) normal renal, thyroid and adrenal functioning; (5) disappearance of all symptoms following water restriction; and (6) no previous diuretic therapy. This last criterion eliminated SIADH as the etiology of Mr. M's hyponatremia since inapamide had been used to treat his hypertension.

When a needed psychotropic medication is suspected of causing the electrolyte disturbance, a drug rechallenge under close monitoring for several days, or a water loading test with measurement of urine osmolarity is indicated. In Mr. M's case, the neuroleptic was restarted without a return of the hyponatremia, thus excluding fluphenazine as the cause of the hyponatremia.

Psychogenic polydipsia has been implicated as a causal factor in hyponatremia, with the most common concurrent diagnosis being chronic undifferentiated schizophrenia (5). A recent epidemiological evaluation found a $17.5 \%$ prevalence of psychogenic polydipsia in over 200 psychiatric inpatients (6). The specific mechanism of this disorder has not been clearly established, but numerous hypotheses coexist. Delusions and command hallucinations may play a role in excessive water consumption. Also, many patients receiving neuroleptic medication also take concomitant antiparkinsonian medications which may potentiate anticholinergic side effects and cause dry mouth. 
Dysfunction of central nervous system osmotic receptors may also play a role in psychogenic polydipsia. Chronic polydipsia may then lead to a further resetting of the receptors to maintain a lower serum osmolality. Hypothalamic dopaminergic pathways are involved in the regulation of thirst and $\mathrm{ADH}$ release. Destruction of these pathways in cats diminishes $\mathrm{ADH}$ release and leads to adipsia. Antipsychotic medications, which cause dopamine receptor blockade, produce a similar effect when injected centrally. A mechanism similar to tardive dyskinesia has been hypothesized, wherein chronic dopamine blockade from antipsychotic therapy can lead to a denervation hypersensitivity in these hypothalamic tracts (7). This would in turn produce increased $\mathrm{ADH}$ release and thirst, with subsequent water intoxication. If this latter mechanism is correct, continued use of the antipsychotic could render a temporary symptom permanent. Further research will be necessary to clarify these issues.

In Mr. M's case the recent initiation of antihypertensive therapy with the thiazide-like diuretic inapamide further clouded the picture. Though diuretics are well known to cause hypo-osmolar syndromes, severe hyponatremia is relatively uncommon. A recent report, however, described 25 patients on chronic diuretic therapy who developed severe hyponatremia and hypokalemia without neurologic sequelae that were rapidly corrected with adequate sodium intake and discontinuation of the medication (8). In these cases, it appeared that diuretic-induced potassium depletion resulted in increased $\mathrm{ADH}$ secretion. Diuretic-induced hyponatremia shares all the above features of SIADH, but in addition is accompanied by hypokalemia.

A more fulminant hyponatremic course has been described, in which seven patients receiving diuretic therapy for an average of 16 days developed severe hyponatremia and neurologic symptoms (9). Other causes of the neurologic symptoms seen were ruled out with CT scans and lumbar punctures. Only two of the seven patients survived; on subsequent examination no evidence of SIADH was present. It was hypothesized that this group had a severe and rapidly developing salt-losing nephropathy of uncertain etiology. It appears that $\mathrm{Mr}$. M may have shared this mechanism for his hyponatremia, since he had recently been started on inapamide, and his fluphenazine therapy had not fluctuated for several years.

Abramow outlined clinical characteristics that place an individual at risk for diuretic-induced hyponatremia (10). Increased age is an important variable, with a mean age of over 75 years noted by Abramow. He also found an 11:1 female to male incidence of this disorder, despite a 1:2 female to male ratio of diuretic therapy. The majority of patients studied were being treated for arterial hypertension and many were of below average body weight.

A final factor to be considered in any case of hyponatremia is the role of tobacco smoking. Nicotine has long been known to be a potent stimulus to the release of $\mathrm{ADH}$. Although smoking appears to be a very common phenomenon among patients with chronic psychiatric disorders, very little consideration has been given it as a possible cause of hyponatremia. In Blum's review of 31 articles 
on water intoxication, it was noted that none had considered smoking as a possible cause of the disorder (11). Blum reported on a patient with hyponatremia which appeared to be secondary to nicotine-induced ADH secretion. Because of nicotine's role as a potent $\mathrm{ADH}$ releasing agent, smoking history and practice warrants assessment in the evaluation of hyponatremia.

\section{TREATMENT}

Water restriction remains the hallmark of treatment, with regulation of potassium and magnesium as needed. In some psychiatric patients, however, water restriction may be difficult or at times impossible, and thus oral sodium supplementation may be substituted in some less severe cases (12). In severely symptomatic patients with hyponatremia, intravenous sodium replacement is necessary, but the rate of replacement remains in dispute. If sodium is replaced too rapidly, extrapontine myelinolysis may occur, while if replaced too slowly excessive mortality may result (13). There have been reports of demeclocycline being effective as an inhibitor of $\mathrm{ADH}(14)$; it may thus have a role in the normalization of sodium.

If drug-induced SIADH is suspected, the offending agent must be discontinued. In psychiatric disorders such as schizophrenia, however, this may lead to a recurrence of psychotic symptoms. Such recurrence may require switching to another class of neuroleptic, or restarting the suspected medication at the minimum effective dose, with serial measurement of electrolytes over several days. This rechallenge would confirm the etiology of the disorder if the patient becomes hyponatremic as the medication is restarted. Obviously, if diuretic therapy is suspected of causing the disorder, the drug should be discontinued and an alternate form of antihypertensive treatment should be initiated. Discontinuation of smoking may also be necessary to prevent exogenous stimulation of $\mathrm{ADH}$ release.

\section{SUMMARY}

Hyponatremia may be a more common disorder than previously recognized, especially in the psychiatric population. The case of $\mathrm{Mr}$. M emphasizes the importance of evaluating organic etiologies for what may seem to be purely psychiatric symptoms, and remembering that not all that appears psychiatric is psychiatric. Once hyponatremia is discovered in a psychiatrically ill patient, the potential causal factors are often difficult to fully separate. As described, one must consider the contributions of neuroleptic medications, compulsive water consumption, diuretic therapy, and smoking. Further research on the hypothesis that hypothalamic denervation hypersensitivity produces a tardive-like phenomena that may lead to chronic water intoxication and hyponatremia would help separate these causative factors and help direct treatment approaches. 


\section{ACKNOWLEDGEMENT}

The author would like to acknowledge the guidance and inspiration provided by Stephen L. Ruedrich, M.D., Associate Professor, Cleveland Metropolitan General Hospital in Cleveland, Ohio.

\section{REFERENCES}

1. Gleadhill IC, Smith TA, Yium JJ: Hyponatremia in patients with schizophrenia. South Med J 1982; 75:426-428

2. Sandifer MG: Hyponatremia due to psychotropic drugs. J Clin Psychiatry 1983; 44:301-303

3. Kosten TR, Camp W: Inappropriate secretion of $\mathrm{ADH}$ in a patient receiving piperazine phenothiazines. Psychosomatics 1980; 21:351-55

4. Bartter FC, Schwartz WB: The syndrome of inappropriate secretion of antidiuretic hormone. N J Medicine, 1967; 42:790-801

5. Kirch DG, Bigelow LB, Weinberger DR, et al: Polydipsia and chronic hyponatremia in schizophrenic inpatients. J Clin Psychiatry 1985; 46:179-181

6. Blum A, Tempey F, Lynch W: Somatic findings in patients with psychogenic polydipsia. J Clin Psychiatry 1983; 44:55-6

7. Smith WO, Clark ML: Self-induced water intoxication in schizophrenic patients. Am J Psychiatry 1980; 137:1055-1060

8. Fichman MP, et al: Diuretic induced hyponatremia. Ann Intern Med 1971; 75:853863

9. Ashraf N, et al: Thiazide-induced hyponatremia associated with death or neurologic damage in outpatients. Am J Med 1981; 70:1163-1168

10. Abramow M, Cogen E: Clinical aspects and pathophysiology of diuretic induced hyponatremia. Adv Nephrol 1984; 13:1-28

11. Blum A: The possible role of tobacco cigarette smoking in hyponatremia of long-term psychiatric patients. JAMA 1984;252:2864-5

12. Vieweg WVR, Rowe WT, David JJ, et al: Oral sodium chloride in the management of schizophrenic patients with self-induced water intoxication. J Clin Psychiatry 1985; 46:16-19

13. Mozes B, Pines A, et al: Thiazide-induced hyponatremia: an unusual neurologic course. South Med J 1986; 79:629-31

14. Forrest JN, et al: Superiority of demeclocycline over lithium in the treatment of chronic SIADH. N Engl J Med 1978; 298:173-177 